\title{
Calibration Calculations of Hadronic Cascades Induced by High-Energy Muons in Iron/Plastic Calorimeters
}

\author{
T. A. Gabriel \\ J. D. Amburgey
}

\section{MASTER}

\section{OAK RIDGE NATIONAL LABORATORY}

OPERATED BY UNION CARBIDE CORPORATION FOR THE ENERGY RESEARCH AND DEVELOPMENT ADMINISTRATION 


\section{DISCLAIMER}

This report was prepared as an account of work sponsored by an agency of the United States Government. Neither the United States Government nor any agency Thereof, nor any of their employees, makes any warranty, express or implied, or assumes any legal liability or responsibility for the accuracy, completeness, or usefulness of any information, apparatus, product, or process disclosed, or represents that its use would not infringe privately owned rights. Reference herein to any specific commercial product, process, or service by trade name, trademark, manufacturer, or otherwise does not necessarily constitute or imply its endorsement, recommendation, or favoring by the United States Government or any agency thereof. The views and opinions of authors expressed herein do not necessarily state or reflect those of the United States Government or any agency thereof. 


\section{DISCLAIMER}

Portions of this document may be illegible in electronic image products. Images are produced from the best available original document. 


\section{Printed in the United States of America. Available from National Technical Information Service \\ U.S. Department of Commerce \\ 5285 Port Royal Road, Springfield, Virginia 22161 \\ Price: Printed Copy $\$ 4.00 ;$ Microfiche $\$ 3.00$}

This report was prepared as an account of work sponsored by the United States Government. Neither the United States nor the Energy Research and Development Administration/United States Nuclear Regulatory Commission, nor any of their employees, nor any of their contractors, subcontractors, or their employees, makes any warranty, express or implied, or assumes any legal liability or responsibility for the accuracy, completeness or usefulness of any information, apparatus, product or process disclosed, or represents that its use would not infringe privately owned rights. 


\title{
CALIBRATION CALCULATIONS OF HADRONIC CASCADES INDUCED BY HIGH-ENERGY MUONS IN IRON/PLASTIC CALORIMETERS*
}

\author{
T. A. Gabriel \\ J. D. Amburgeyt
}

Date Published: December 1976

* Submitted for journal publication.

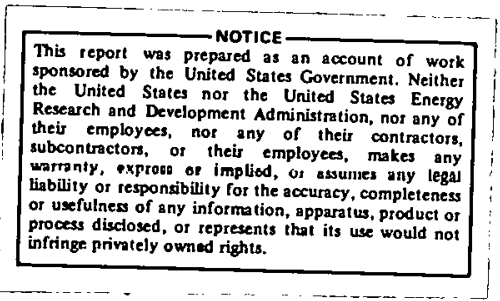
tComputer Sciences Division.

NOTICE This document contains information of a preliminary nature. It is subiect to revision or correction and therefore dóes not represent a final report.

OAK RIDGE NATIONAL LABORATORY

Oak Ridge, Tennessee, 37830

operated by

UNION CARBIDE CORPORATION

for the

ENERGY RESEARCH AND DEVELOPMENT ADMINISTRATION 


\section{THIS PAGE \\ WAS INTENTIONALLY \\ LEFT BLANK}




\section{Abstract}

Calculations have been performed to determine the response of an iron-plastic calorimeter to muon-induced nuclear interactions. The calculated data include energy resolutions and average pulse-height signals as a function of energy transfer, energy-transfer angle, and spatialinteraction point. 
THIS PAGE

\section{WAS INTENTIONALLY \\ LEFT BLANK}




\section{Acknowledgment}

The authors wish to thank Dr. Lawrence Litt of Michigan State University for pointing out the need for these calculations and for his many helpful comments and suggestions. 


\section{INTRODUCTION}

Calorimeters that are used to detect low-probability muon-nuclear interactions are usually substantially larger in the longitudinal direction than are the typical $\sim 1000-\mathrm{g} / \mathrm{cm}^{2}$-thick hadronic devices. A large longitudinal device ensures that the muon has a reasonable chance for interaction at a sufficient distance upstream from the end of the calorimeter so that the ensuing energy transferred to the hadronic and/or electromagnetic cascade can be contained. The transverse dimensions of the muon calorimeter do not necessarily have to be much larger than those of typical hadronic devices since the angles associated with the transferred energy are usually small.

Presented in this paper are calculated calibration data for a muon calorimeter composed of 104 iron blocks $\left(25.4 \times 25.4 \times 5.08 \mathrm{~cm}^{3}\right)$ sandwiched between 104 plastic sheets $\left(25.4 \times 25.4 \times 0.953 \mathrm{~cm}^{3}\right)$; no gaps between the iron and plastic have been introduced. The energy range, i.e., the range of energy transferred by the muon to the hadronic and/or electromagnetic cascade, considered in these calculations is 20 to $180 \mathrm{GeV}$. The energytransfer angle range, i.e., the angle range in which the hadronic and/or electromagnetic cascade is generated, is 0 to $200 \mathrm{mrad}$. The calculated data include energy resolutions and average pulse-height signals as a function of energy transfer, energy-transfer angle, and spatial-interaction point, as well as selected pulse-height distributions. Some comparisons are also made with experimental data to partly validate the results.

Other than the approximation associated with the initial muon-nuclear interaction, the methods employed in the calculations are the same as those discussed previously $y^{1-3}$ ). To obtain the type and momentum of particles 
that emerge from a muon-induced star, it was assumed that particles emerging from $x-G e V$ proton stars are similar to those that are expected from muoninduced stars when the transfer of energy amounts to $x-G e V$.

\section{CALCULATED RESULTS AND DISCUSSION}

In all the results presented here the ionization signal of the muon has been omitted. If a minimum ionizing muon transverses the entire device, the total signal can amount to $\sim 200 \mathrm{MeV}$.

The resolution of the muon calorimeter as a function of energy transfer, energy-transfer angle, and radial distance from the center of the calorimeter is given in fig. la and $b$. These data are for muon collisions which occur in the iron blocks $>10$ but 480 . Also included in fig. ib is a comparison with experimental $\mathrm{data}^{4}$ ) for incident 30-, 60-, 90-, and 150-GeV hadrons. The calorimeter used to obtain the experimental data is basically the same as the one described here except longitudinally it is much shorter $\left(\sim 1000 \mathrm{~g} / \mathrm{cm}^{2}\right)$. The agreement is quite good.

The increase in the resolution, as indicated in fig. la, as the initial interaction point approaches the edge of the calorimeter is due to a rapid increase in the amount of transverse leakage energy. It has been pointed out many times ${ }^{5,6}$ ) that small changes in the total signal can have a drastic effect upon the performance of a calorimeter. This increase in lateral hadronic energy loss for 50- and 95-GeV energy transfers is shown in fig. 2 as a function of energy-transfer angle and radial distance from the edge of the calorimeter.

The longitudinal variations of the resolution for 0 - and 200-mrad energy-transfer angles are presented in figs. 3 and 4 , respectively, as a function of energy transfer, radial distance from the center of the 

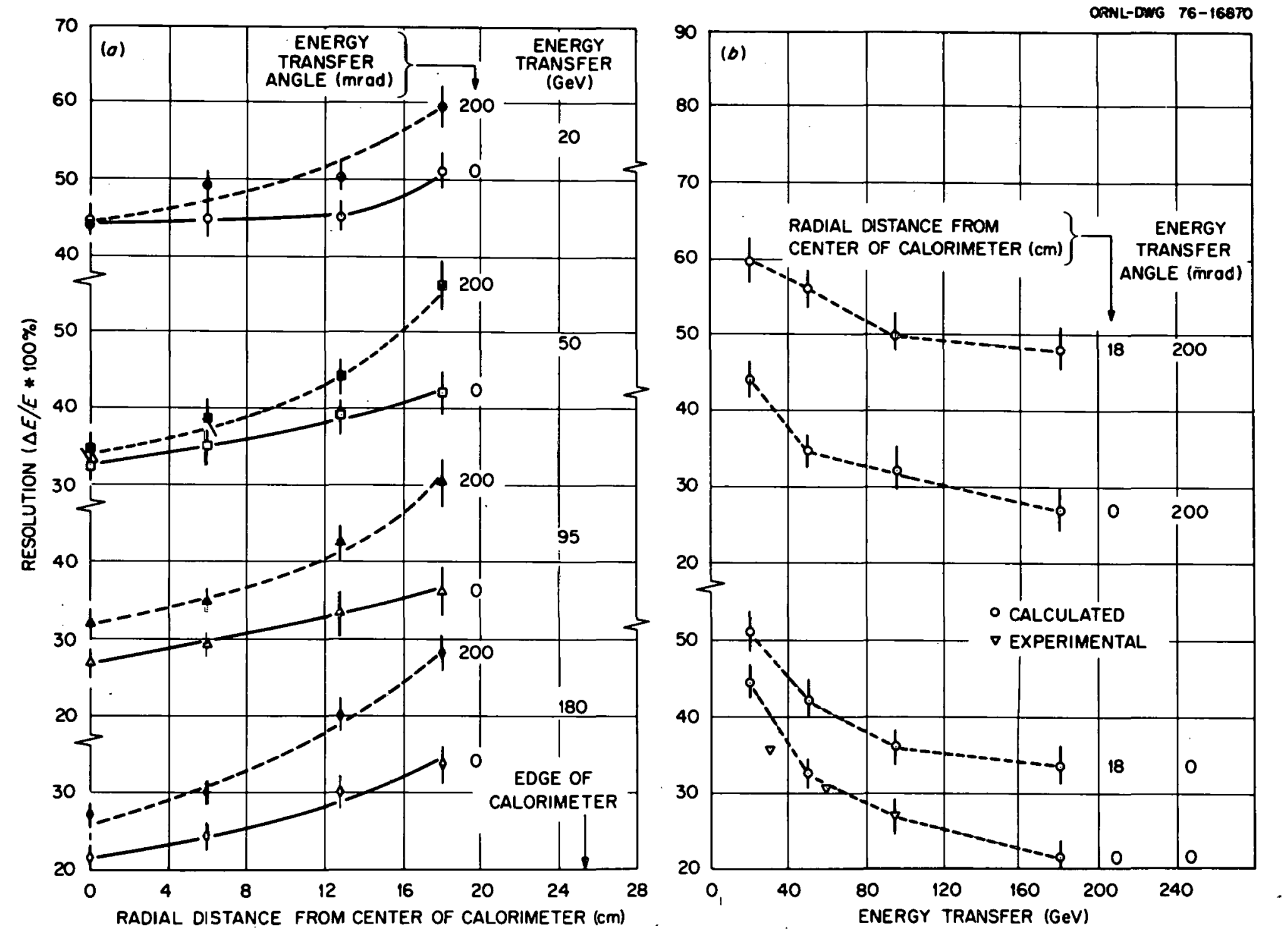

Fig. 1. Resolution of the muon calorimeter as a function of energy transfer, energytransfer angle, and radial distance from the center of the calorimeter. 


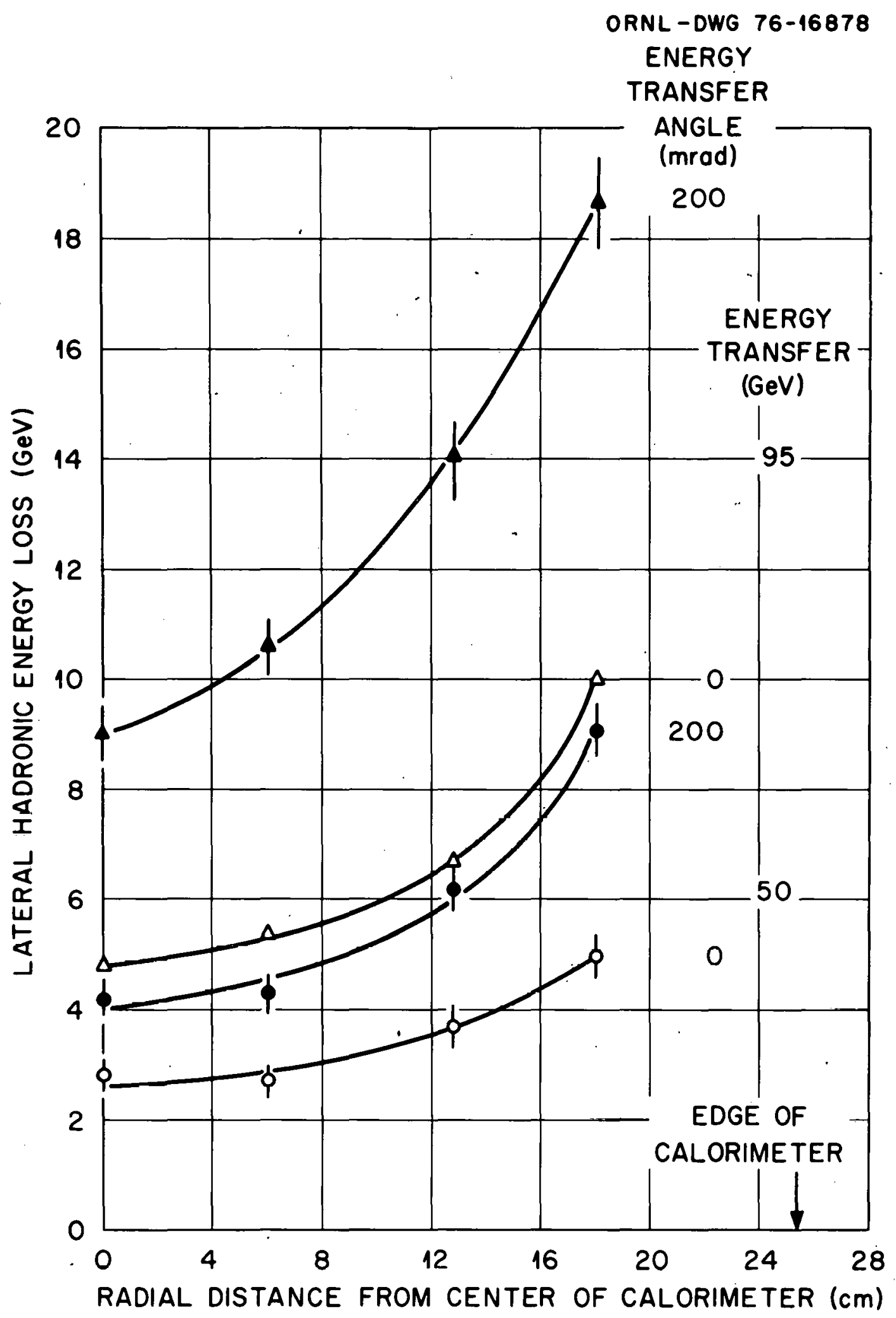

Fig. 2. Lateral hadronic energy loss as a function of energy transfer, energy-transfer angle, and radial distance from the center of the calorimeter. 


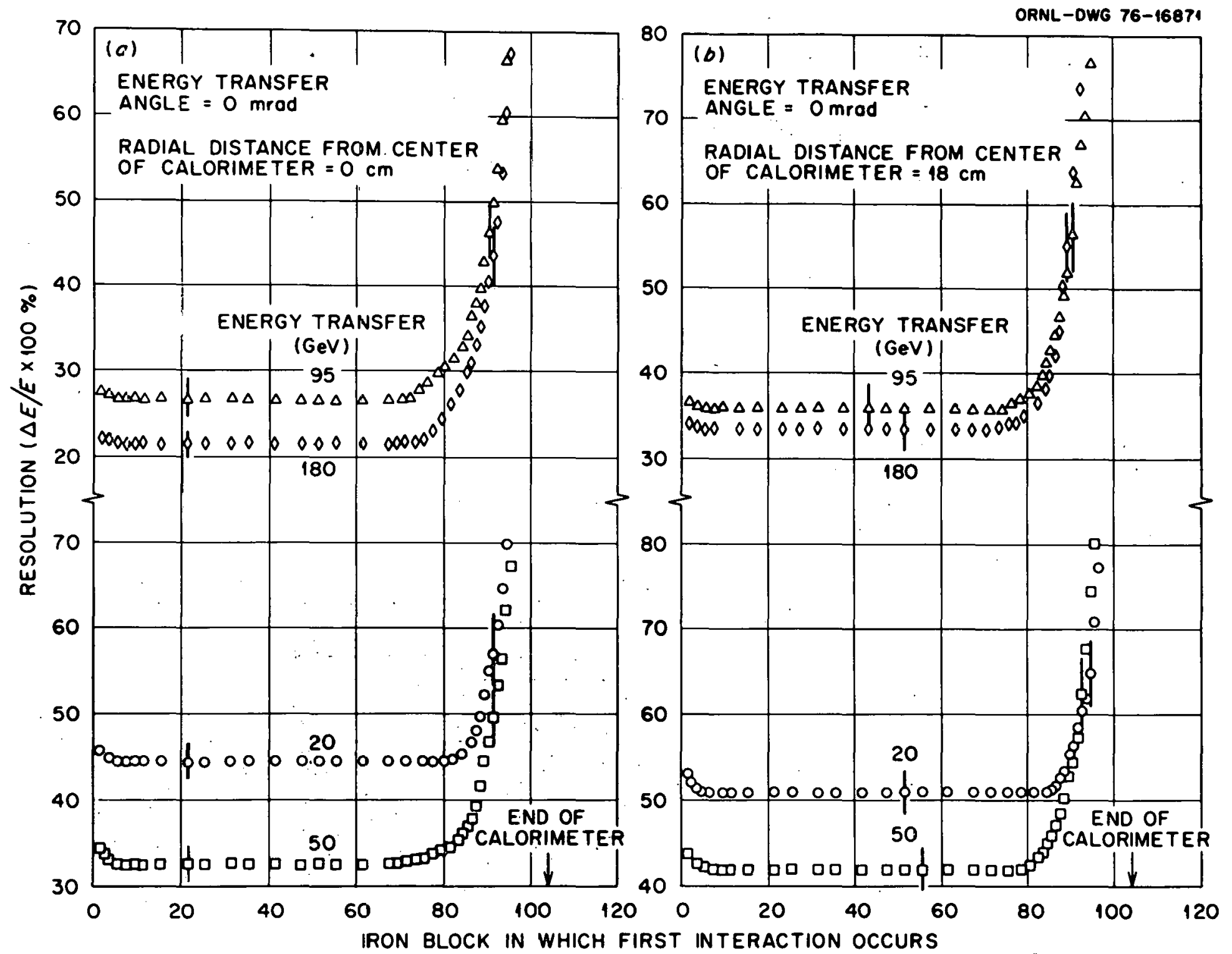

Fig. 3. Longitudinal variation of the resolution as a function of energy transfer, radial distance from the center of the calorimeter, and the iron block in which the first interaction occurs for an energy-transfer angle of 0 mrad. 

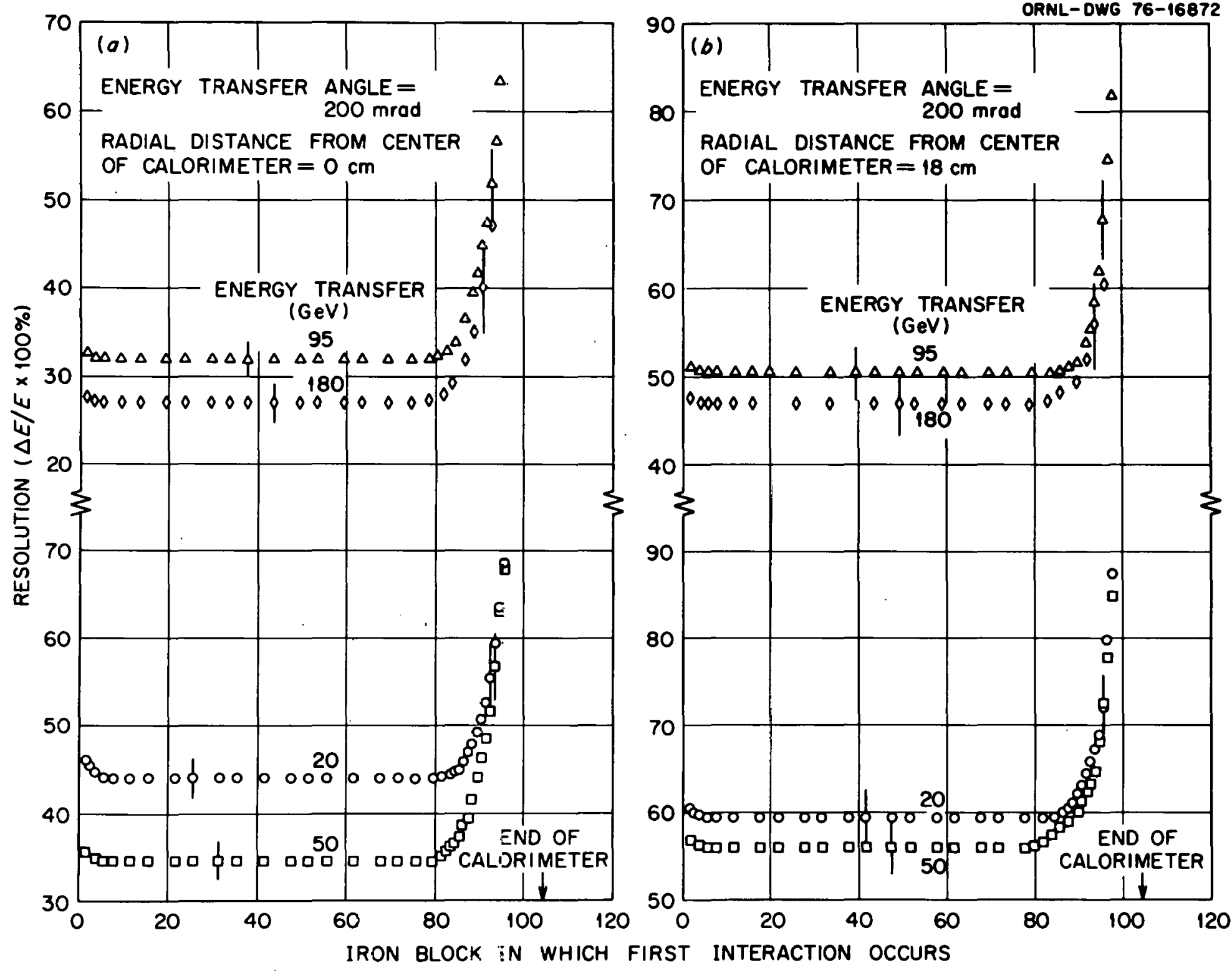

Fig. 4. Longitudinal variation of the resolution as a function of energy transfer, radial distance from the center of the calorimeter, and the iron block in which the first interaction occurs for an energy-transfer angle of $200 \mathrm{mrad}$. 
calorimeter, and the iron block in which the first interaction occurs. No requirements are placed on the intial muon star produced in the nth iron block - for example, more electromagnetic than hadronic or vice versa.

The average pulse-height signal as a function of energy transfer, energy-transfer angle, and radial distance from the center of the calorimeter for the initial interaction occurring in iron blocks $\geqslant 10$ but $<80$ is shown in fig. 5. Given in fig. 6 are similar data but with no restriction on the initial interaction.

Additional comparisons between the present calculated results and experimental data ${ }^{7-9}$ ) are given in fig. 7. An exact comparison is not possible as the calorimeters and particle energies in the figure are not totally equivalent to those considered here. However, general trends should exist. The comparison with the data of Baum et az. ${ }^{7}$ ) (fig. 7a) is quite good and shows how the pulse-height signal and resolution should change as the thickness of the calorimeter is reduced. Similar comparisons are shown in fig. $7 b$ and $7 c$.

In determining the location of the first star, experimentalists often favor initial collisions which yield large electromagnetic or hadronic components, thereby obtaining smaller resolutions and shorter containment distances than would be the case if no restrictions were placed on the initial collision. This trend is shown in fig. $7 \mathrm{~b}$ and $\mathrm{c}$ by comparing the calculated data when no restrictions are placed on the initial collision and when a set of conditions must be met before, by definition, an initial collision has occurred at a given point in the calorimeter. It should be pointed out that no restrictions on the initial interaction have been placed on the majority of the data presented. Therefore, if stringent requirements are 


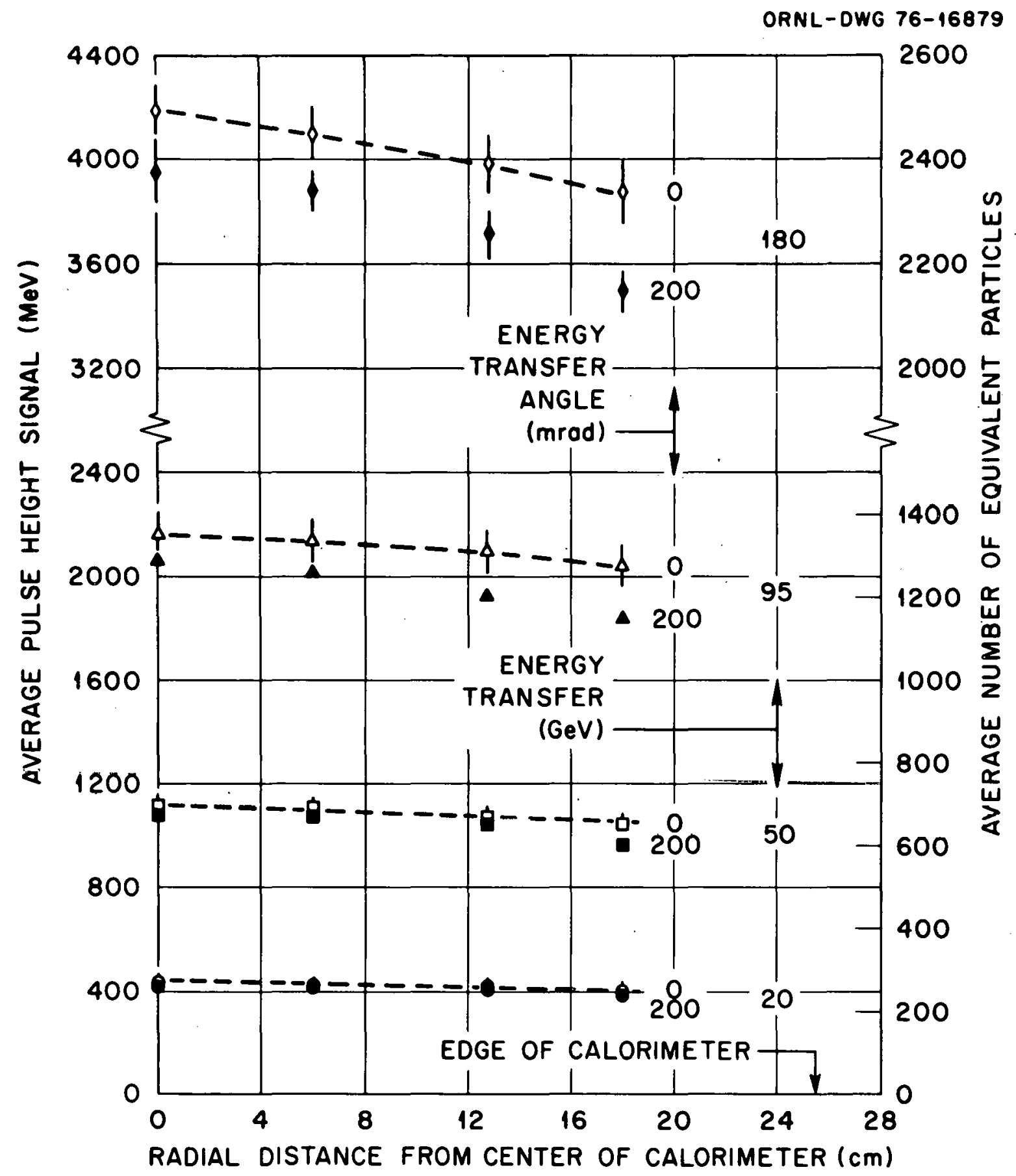

Fig. 5. Average pulse-height signal as a function of energy transfer, energy-transfer angle, and radial distance from the center of the calorimeter. (Initial interactions occur in iron blocks $>10$ but $<80$.) 

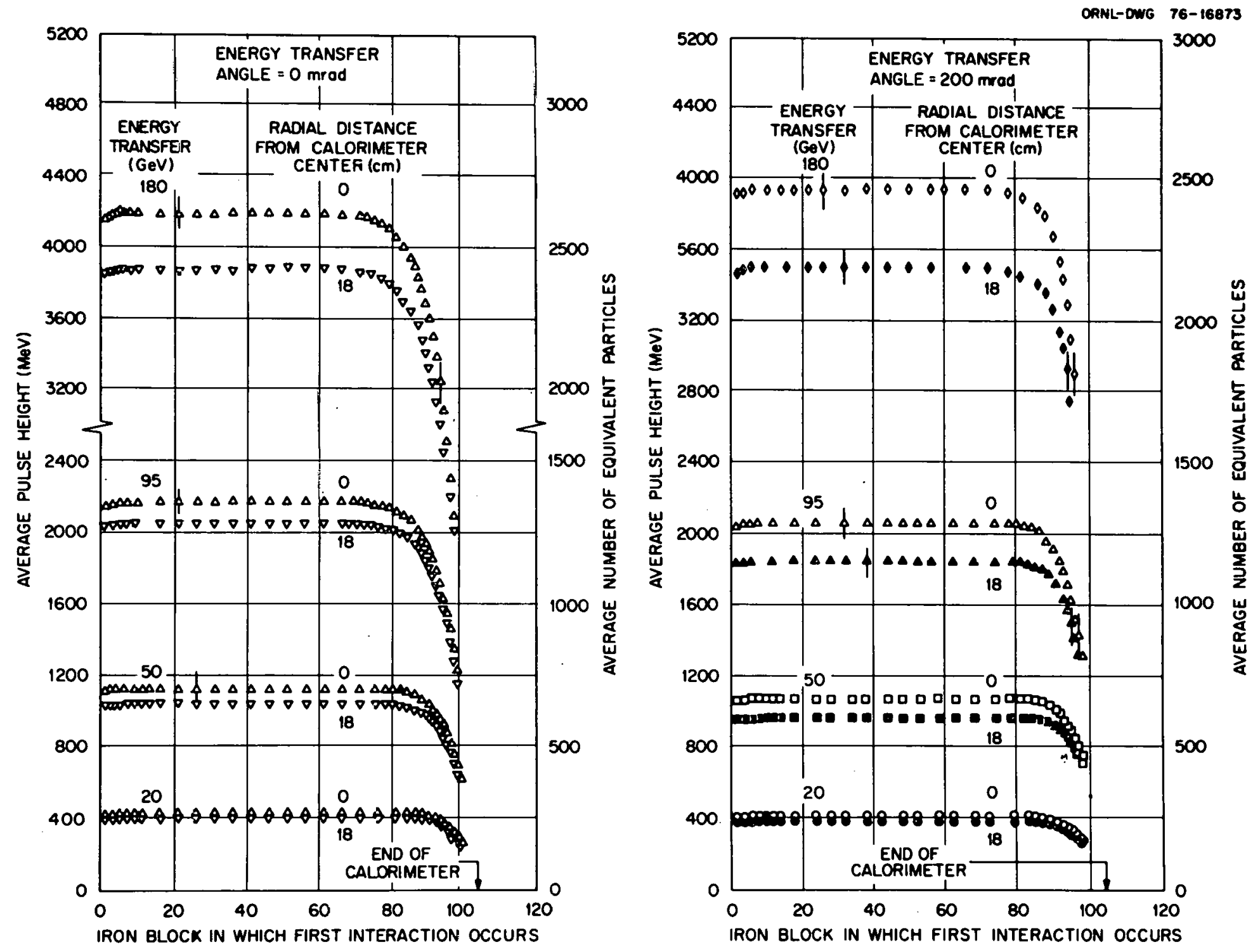

Fig. 6. Average pulse-height signal as a function of energy transfer, energy-transfer angle, radial distance from the center of the calorimeter, and the iron block in which the first interaction occurs. 

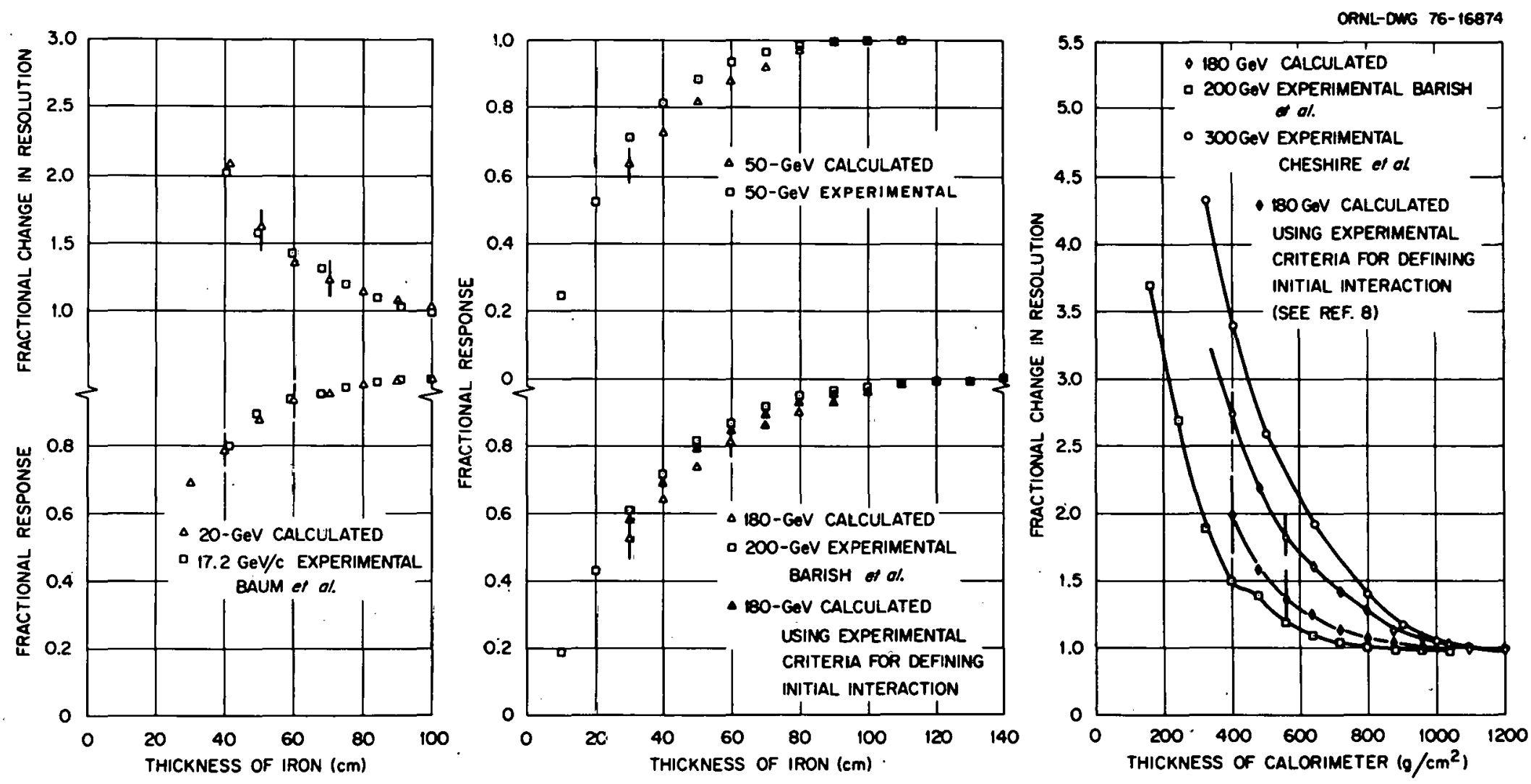

Fig. 7. Variations in the average pulse-height signal and resolution due to a decrease in calorimeter thickness. 
placed on defining an initial collision, then this should be taken into account when using the data given here.

In figs. 8,9 , and 10 are shown representative pulse-height distributions for different energy transfers, energy-transfer angles, radial distances from the center of the calorimeter, and the iron block in which the first interaction occurs. 

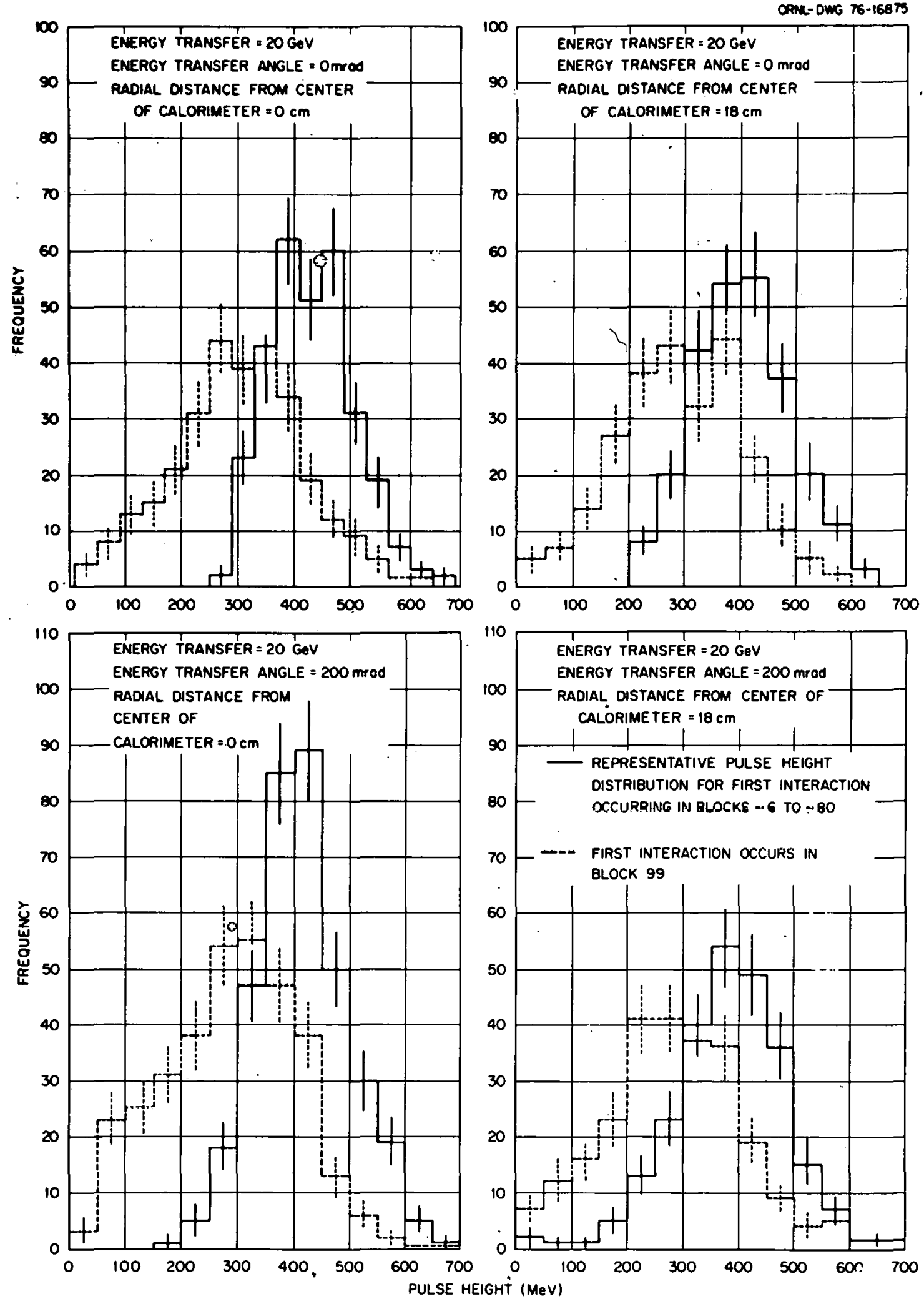

Fig. 8. Pulse-height distributions for energy transfers of $20 \mathrm{GeV}$. 

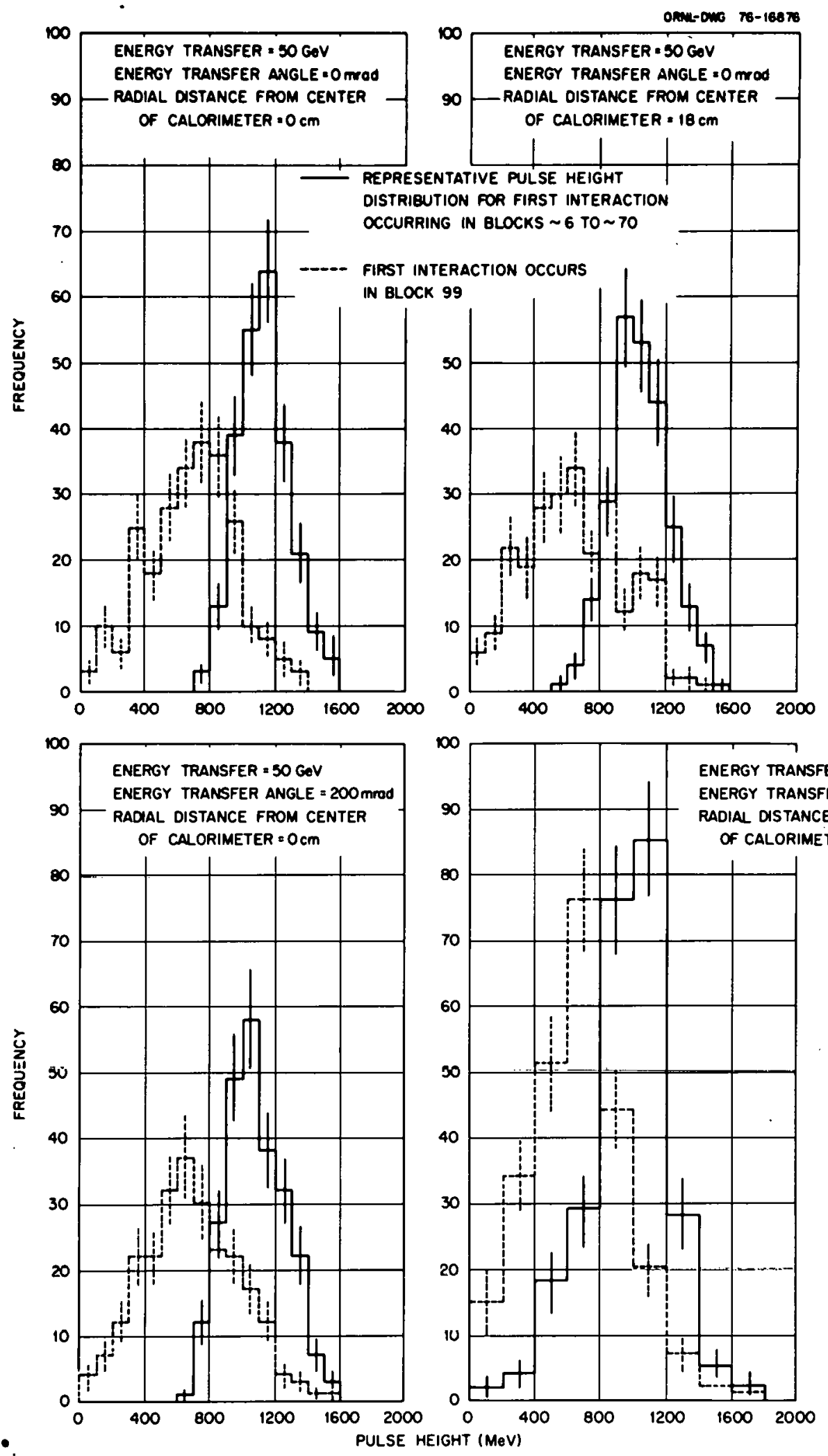

Fig. 9. Pulse-height distributions for energy transfers of $50 \mathrm{GeV}$. 

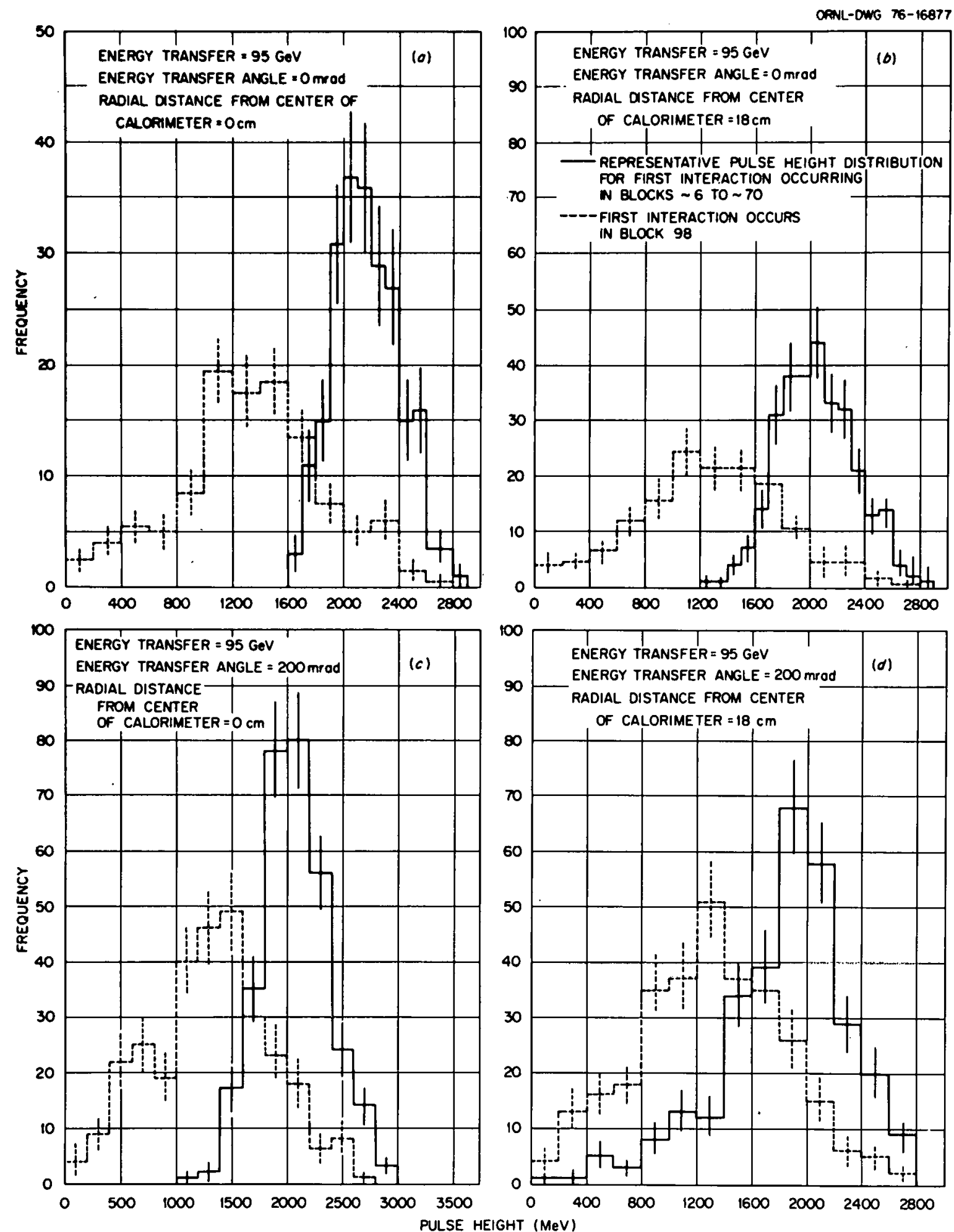

Fig. 10. Pulse-height distributions for energy transfers of $95 \mathrm{GeV} .{ }^{\circ}$ 


\section{REFERENCES}

1T. A. Gabriel, J. D. Amburgey, and R. T. Santoro, Nucl. Instr. Meth. 129 (1975), 409.

${ }^{2}$ T. A. Gabriel and J. D. Amburgey, Nucl. Instr. Meth. 116 (1974) 333.

${ }^{3}$ T. A. Gabriel and W. Schmidt, Nucl. Instr. Meth. 134 (1976) 271.

${ }^{4}$ Lawrence Litt, Michigan State University, preliminary data. Additional and more extensive measurements have been made. The data analys is is now in progress.

5W. Selove et al., "Some Early Results from a Segmented Calorimeter," Proc. of the Calorimeter Workshop, Fermi National Accelerator Laboratory, Batavia, Illinois, May 1975, p. 271.

${ }^{6} W$. Selove, University of Pennsylvania, private communication.

${ }^{7} \mathrm{~L}$. Baum et al., "Design and Performance of a Liquid Scintillator/Iron Sandwich Calorimeter Used at the ISR," Proc. of the Calorimeter Workshop, Fermi National Accelerator Laboratory, Batavia, Illinois, May 1975, p. 295. BB. C. Barish et al., "Calibration of a Sampling Total Absorption Detector Designed for Neutrino Experiments," ibid. p. 229.

${ }^{9} \mathrm{D}$. L. Cheshire et al., "Response of a Tungsten Calorimeter to FNAL Proton Beams," ibid. p. 263. 


\section{THIS PAGE}

\section{WAS INTENTIONALLY \\ LEFT BLANK}


Internal Distribution

ORNL/TM-5615
1-2. L. S. Abbott
3. F. S. Alsmiller
4. R. G. Alsmiller, Jr.
5-9. J. D. Amburgey
10. H. W. Bertini
11-39. T. A. Gabriel
40. F. C. Maienschein
41. F. R. Mynatt
42. E. M. Oblow
43. R. W. Roussin
44. RSIC
45. R. T. Santoro
46. M. L. Tobias

47. C. R. Wetsbin

48. G. E. Whitesides

49. A. Zucker

50. P. Greebler (Consultant)

51. W. W. Havens, Jr. (Consultant)

52. A. F. Henry (Consultant)

53. R. E. Uhrig (Consultant)

54-55. Central Research Library

56. ORNL Y-12 Technical Library, Document Reference Section

57. Laboratory Records Department

58. Laboratory Record-RC

59. ORNL Patent Office

\section{External Distribution}

60. C. Fabjan, CERN, Geneva 23, Switzerland.

61. W. T. Ford, Fermi National Accelerator Laboratory, P. 0. Box 500, Batavia, IL 60510.

62. H. Goldstein, Columbia University, 287A Mudd Building, New York, NY 10027.

63. J. Kirkby, Stanford Linear Accelerator Center, P. O. Box 4349, Stanford, CA 94305.

64. L. Litt, Department of Physics, Michigan State University, East Lansing, MI 48823.

65. W. Schmidt, Institute of Experimental Nuclear Physics, University of Karlsruhe, 75 Karlsruhe, Germany.

66. A. L. Sessoms, Department of Physics, Harvard University, Cambridge, MA 02138.

67. L. R. Sulak, 252 Jefferson Laboratory, Harvard University, Cambridge, MA 02138.

68. W. J. Willis, CERN, Geneva 23, Switzerland.

69-95. Technical Information Center (TIC).

96. U.S. ERDA Oak Ridge Operations, Research and Technical Support Division, P. O. Box E, Oak Ridge, TN 37830: Director.

97-127. Given High-Energy Accelerator Shielding distribution. 